$12-2013$

\title{
Obesity and Physical Function in Rural Women who enroll in a Lifestyle Modification Intervention for Reducing Blood Pressure
}

\author{
Patricia A. Hageman \\ University of Nebraska Medical Center, phageman@unmc.edu \\ Carol H. Pullen \\ University of Nebraska Medical Center, chpullen@unmc.edu \\ Paul J. Dizona \\ University of Nebraska Medical Center, pjdizona@unmc.edu \\ Kristin Schmidt \\ University of Nebraska Medical Center \\ Linda S. Boeckner \\ University of Nebraska-Lincoln, lboeckner1@unl.edu
}

Tell us how you used this information in this short survey.

Follow this and additional works at: https://digitalcommons.unmc.edu/sahp_pt_articles

Part of the Physical Therapy Commons

\section{Recommended Citation}

Hageman, Patricia A.; Pullen, Carol H.; Dizona, Paul J.; Schmidt, Kristin; and Boeckner, Linda S., "Obesity and Physical Function in Rural Women who enroll in a Lifestyle Modification Intervention for Reducing Blood Pressure" (2013). Journal Articles: Physical Therapy. 4.

https://digitalcommons.unmc.edu/sahp_pt_articles/4

This Article is brought to you for free and open access by the Physical Therapy at DigitalCommons@UNMC. It has been accepted for inclusion in Journal Articles: Physical Therapy by an authorized administrator of DigitalCommons@UNMC.For more information, please contact digitalcommons@unmc.edu. 


\section{Obesity and Physical Function in Rural Women who enroll in a Lifestyle Modification Intervention for Reducing Blood Pressure}

Patricia A. Hageman, PT, $\mathrm{PhD}^{1}$, Carol H. Pullen, RN, EdD ${ }^{2}$, Paul Dizona, $\mathrm{MS}^{2}$, Kristin Schmidt, PT, DPT ${ }^{1}$, Linda S. Boeckner, RD, $\mathrm{PhD}^{3}$

\footnotetext{
${ }^{1}$ Physical Therapy Education, School of Allied Health Professions, College of Medicine, University of Nebraska Medical Center, Omaha, NE

${ }^{2}$ College of Nursing, University of Nebraska Medical Center, Omaha, NE

${ }^{3}$ College of Education \& Human Services, University of Nebraska-Lincoln, Lincoln, NE
}

\section{Author Information:}

Corresponding Author: Patricia A. Hageman, PT, PhD, Physical Therapy Education, School of Allied Health Professions, College of Medicine, University of Nebraska Medical Center, Omaha, Nebraska, USA, Phone: 402-559-1967, Fax 402-559-8626, phageman@unmc.edu 


\section{ABSTRACT}

Purpose: Rural women have high prevalence of obesity and prehypertension. Obesity, if associated with poor physical function, may have implications for applying activity guidelines for women volunteering for lifestyle modification. This study examined associations of body mass index (BMI) and percent body fat with measures of 1-mile walk time, post-walk perceived exertion, and 10-repetition chair stands in rural women ages 40-69. Methods: Cross-sectional baseline data were collected using standardized methods from 289 rural women with prehypertension who volunteered for a lifestyle clinical trial for reducing blood pressure. ANOVAs and linear regression were used for analysis. Results: With exception of the chair stands measure across categories of BMI, group differences were noted in all measures across categories of BMI and percent body fat, with women in the two highest categories demonstrating the poorest performance. These two body composition measures were significant predictors for 1-mile walk-time and 10-repetition chair stands, after controlling for confounding variables. Conclusions: Poorer scores were observed in performance-based measures in women with higher BMI and percent body fat, though mean scores were above thresholds for functional limitation. Physical performance needs to be assessed and addressed by physical therapists when providing lifestyle interventions for overweight and obese women.

Key Words: obesity, physical function, rural, midlife and older women 


\section{INTRODUCTION}

According to data from the National Health and Nutrition Examination Survey (NHANES), middle-aged adults have the highest prevalence of obesity and the prevalence of obesity is higher in rural women than urban residents. ${ }^{1,2}$ Rural Midwestern women have documented higher rates of overweight and obesity, poorer self-reported health and less access to preventive services compared to their urban counterparts. ${ }^{3,4}$ As such, women in underserved rural communities have been targeted as priority populations for research to address cardiovascular risk and other health disparities by agencies with the US Department of Health and Human Services, such as the National Institutes of Health and the Agency for Healthcare Quality and Safety. 5,6

The increased prevalence of obesity in midlife and older adults is a concern as there is compelling evidence of a strong association between obesity and impaired physical function in later life. ${ }^{7,8}$ Physical function refers to a person's ability to perform activities of daily living, and impaired physical function is commonly measured using self-report or performance-based measures of gait or muscle strength. ${ }^{7-10}$ In an analysis of 13 crosssectional and 15 longitudinal studies of men and women over 60 , Vincent and colleagues ${ }^{10}$ reported a consistent finding that walking, stair climbing, and chair rise ability are compromised with obesity especially if BMI is greater than 35 . Obese women appear to be at higher risk for mobility impairment than men. ${ }^{8}$

The majority of studies investigating associations between obesity and physical function have been conducted in older populations ( $>60$ years) and/or defined physical function via self-report, or used physical performance tests appropriate for sedentary adults or individuals with chronic diseases. ${ }^{7,8,11-17}$ Examples of performance-based measures used in prior studies of sedentary or older adults include the Timed Up and Go Test and the 5repetition timed chair stands; measures that may not distinguish ability among middle-aged 
individuals and/or individuals who have higher functional capacity as adequately as the more challenging physical measures of 1-mile walk time and 10-repetition timed chair stands. ${ }^{18,19}$

Obesity is most frequently defined by BMI because it is an easy to assess and convenient measure, although prior studies of the relationship between obesity and physical function more frequently examine fatness by normal weight, overweight, and obesity without specifically distinguishing function across all categories of obesity (obesity I $30-34.9 \mathrm{~kg} / \mathrm{m}^{2}$; obesity II $35-39.9 \mathrm{~kg} / \mathrm{m}^{2}$, and obesity III $\left.>40 \mathrm{~kg} / \mathrm{m}^{2}\right) .{ }^{20}$ The National Institutes of Health BMI-based classification for obesity $\left(\geq 30 \mathrm{~kg} / \mathrm{m}^{2}\right)$ may significantly underestimate the prevalence of obesity, especially in post-menopausal women, when compared to categorizing obesity using percent body fat measurement methods. ${ }^{21-23}$ Body fat categories are defined as fit (<25\%), overweight (25-29.9\%), obese (30-39.9\%), morbid obese (40-44.9\%) and super obese $(>45 \%) .{ }^{21-23}$ No studies were found in the literature that examined the relationship of physical function with weight categories defined by percent body fat. There is merit to investigating associations of physical function across both methods of weight categorization, as percent body fat may be more reflective of the relative loss of lean body mass associated with health risks, and BMI is more practical for use in the clinic. ${ }^{21-23}$

Initial baseline findings reported about this sample of rural women indicated that a large percentage were obese whether classified by NIH-based BMI $(41.8 \%$; $=127)$ or percent body fat $(94 \% ; n=273)$, although our work has not distinguished the prevalence of obesity across the five categories of BMI or percent body fat nor did it examine the physical performance measures reported in this study. ${ }^{4}$

As noted by Ling and colleagues, ${ }^{16}$ current activity recommendations do not distinguish between overweight and obese weight classes in terms of achieving functional mobility outcomes such as daily moderate physical activity for 30 minutes or taking 10,000 steps daily, ${ }^{24-26}$ despite current research showing individuals with Class III obesity having 
greater numbers of chronic conditions and additional barriers to activity. As successful adoption and maintenance of healthy activity and higher fitness among middle-aged women

is associated with lower burden of chronic conditions in older age, ${ }^{9,27}$ it is highly relevant that practitioners are aware of any associations between obesity and function in order to establish individualized realistic activity expectations and goals for women who are motivated to volunteer for lifestyle interventions.

This study fills gaps in the literature as it examines physical function with the higher spectrum of ability across all five categories of BMI and percent body fat, respectively, in a large cohort of midlife and older rural women who were eligible and motivated to volunteer for a lifestyle modification intervention to reduce their blood pressure as part of a community-based clinical trial.

The specific aims of this study were 1) to assess measures of 1-mile walk time, postwalk perceived exertion, 10-repetition chair stands, and waist circumference in midlife and older rural women with prehypertension across all five categories of BMI and percent body fat, respectively, and 2) to examine the associations of BMI and percent body fat with the 1mile walk time and 10-repetition chair stands. We hypothesized that increased body composition would be related to decreased physical performance on functional measures in this population, even after adjusting for other expected confounding variables (age, education, income, comorbidity, and smoking) associated with physical performance. ${ }^{18,19,28}$

\section{METHODS}

\section{Design}

This study analyzed cross-sectional baseline data of women who met eligibility criteria for and provided informed consent to participate in the Wellness for Women: DASHing toward Health community-based clinical trial (Trial registration: ClinicalTrials.gov identifier:

NCT00580528) with baseline assessments conducted 2007-2008. Briefly, this trial compared 
the effectiveness of a theory-based tailored 12-month lifestyle modification intervention for reducing blood pressure, using distance delivery methods via web or mailed-print, as compared to standard advice only among rural women with prehypertension (systolic blood pressure of 120-139 mmHg and/or diastolic blood pressure of 80-89 mmHg). ${ }^{29}$ The lifestyle modification followed the Dietary Approaches to Stop Hypertension (DASH) that included recommendations for evidence-based levels of physical activity. ${ }^{30}$ This approach is the primary recommendation for reducing blood pressure in women with prehypertension. The study received approval by the University Institutional Review Board (approval \# 352-05FB) at the University of Nebraska Medical Center.

\section{Participants}

Women were recruited at free blood pressure screenings held at local health fairs, craft shows, and other social events. If the blood pressure screenings revealed a woman's blood pressure readings were from $10 \mathrm{mmHg}$ below to $10 \mathrm{mmHg}$ above the prehypertension systolic range or five $\mathrm{mmHg}$ below to five $\mathrm{mmHg}$ above the prehypertension diastolic range, the woman was briefly informed about the study.

Women who expressed interest were asked to provide contact information and were asked to follow-up with a screening interview to establish eligibility for the study. If determined eligible through phone screening, women were then requested to attend two visits one week apart to assess blood pressure by research nurses at our local research office to confirm their prehypertension status blood pressure following standardized procedures for blood pressure assessment, after 5 minutes of quiet sitting. ${ }^{31}$ The baseline blood pressure recorded was the mean of the two final blood pressure measurements across the 2 visits. Participants were asked to avoid caffeine, exercise and smoking for at least 30 minutes prior to blood pressure measurements. 
The eligibility criteria included being willing and able to adopt the DASH eating and activity plan and being able to walk one-mile continuously without use of an assistive device. Women were asked to obtain medical clearance from their physician to participate unless they answered "no" to all questions on the Physical Activity Readiness Questionnaire (PARQ). ${ }^{32}$ Women were excluded from the study if they were taking antihypertensive medication, including diuretics or systemic glucocorticoids or if they were insulin-dependent to manage diabetes. Smokers were permitted to enroll with smoking status noted.

Data were collected on 289 rural women with a mean age of 56.4 years $(\mathrm{SD}=6.3)$. These women were primarily non-Hispanic white $(97.2 \%)$, married (83\%), employed outside of the home full- or part-time (79\%), had some education beyond high school (82\%) and lived in a household with $\$ 40,000$ income or more (71.2\%). (See Table 1$)$. When women were asked whether they had ever been told by a physician they had common physiciandiagnosed medical conditions, $63 \%(n=181)$ reported having none, $25 \%(n=73)$ reported one condition, and $12 \%(n=35)$ reported having 2 or more conditions. Of those reporting a medical condition, arthritis was reported by $23 \%$ of the women.

\section{Tests and Measures}

Body composition was measured in three ways: body mass index, percent body fat and waist circumference. Height and weight measures for BMI calculations and percent body fat were measured using the Tanita Model [TBF-215, Tanita Corporation of America, Inc., 2625 S. Clearbrook Dr., Arlington Heights, IL 60005-9824] following the manufacturer's recommendations using at least two trials of measurements until two exact measures of height were obtained. BMI was calculated as weight in kilograms divided by height in meters-squared. ${ }^{20}$ To address the issue of hydration status that influences measurement of percent body fat via bioelectrical impedance, women received instructions to fast within 4 
hours of the assessments, not to exercise within 12 hours of testing, avoid alcohol or diuretics before testing, and to void the bladder within 30 minutes of the bioelectrical impedance analysis. ${ }^{33,34}$ This measure does underestimate percent body fat compared to the underwater weighing and dual X-ray absorptiometry (DXA) methods; however, it has been shown to detect similar changes in percent body fat during weight loss in obese women that were comparable to the magnitude of change as determined via DXA. ${ }^{34}$

Waist circumference was measured by placing a tape in a horizontal plane around the abdomen at the level of the iliac crest. The tape was snug and parallel to the floor but was held without skin compression. The measurement was taken at the end of expiration, with the average of two trials recorded. ${ }^{20}$

Women were asked to walk as fast as possible over 1-mile distance within an indoor corridor of the building while being timed, following the protocol of the 1-mile submaximal walk test which has high test-retest reliability in this population. ${ }^{18,35}$ We reported their results as minutes to complete the walk and converted the results to gait speed $(\mathrm{m} / \mathrm{s})$ to assist in interpretation. Upon completion of the test, women were asked to rate their exertion using the Borg rating of perceived exertion 6-20 scale, which is a widely used reliable tool that has been associated with physiological measures of exercise intensity. ${ }^{36}$

The 10-repetition timed chair stand test was selected as a measure of lower extremity strength due to its documented reliability and validity, as well as the feasibility of its use in midlife and older rural women. ${ }^{19,37}$ Women were instructed to have arms crossed over their chest and were timed during completion of 10 full stands performed as quickly as possible, using a standard height armless chair placed against the wall. One practice stand was conducted prior to testing.

\section{Analysis}


IBM SPSS Statistics, Version 19 for Windows (SPSS Inc, Chicago IL) was used to analyze the data. To address the first purpose of this paper, analysis of variance was used to compare all measures across the five categories of BMI and percent fat, respectively, with Bonferroni post-hoc analyses used for pair-wise comparisons.

Linear regression analyses were used to examine the associations of body composition, measured as either BMI or percent fat, with each of the physical performance measures. Four analyses were conducted 1) BMI predicting 1-mile walk time, 2) percent fat predicting 1-mile walk time, 3) BMI predicting timed chair stands, and 4) percent fat predicting timed chair stands. Because the literature indicates the relationship between age and function and socio-economic variables with physical performance, ${ }^{8,18,19,21,22,28}$ each analysis was structured as a hierarchical model controlling for age, education, income, comorbidity and smoking. The same set of control variables was entered at step 1 in each of the four analyses. At step 2 of each analysis, the specific measure of body composition (BMI or percent body fat) was entered. An alpha of 0.05 was used for all analyses.

\section{RESULTS}

All categories of obesity were represented in this sample of 289 rural women, whether classified by BMI or percent body fat. Greater numbers of women were classified in the two highest categories of obesity when defined by percent body fat as $\geq 40 \%(n=167,57.7 \%)$ than when defined by BMI of $\geq 35 \mathrm{~kg} / \mathrm{m}^{2}(\mathrm{n}=45,15.6 \%)$. Women classified as obese $(30-39.9 \%)$ by percent fat classification had an average BMI $\left(25.9 \mathrm{~kg} / \mathrm{m}^{2}\right)$ that would be considered overweight by BMI classification. Using the criterion established for metabolic syndrome, $76.8 \%(\mathrm{n}=222)$ had a waist circumference $>80 \mathrm{~cm}$. Overall, the average scores for the 1-mile walk test and the 10 -repetition timed chair stands were 17.6 minutes $(\mathrm{SD}=1.9$; range $=13.8-$ 26.5 minutes) and 18.0 seconds $(\mathrm{SD}=4.5$; range $=9.6-33.8$ seconds $)$, respectively. Average scores for perceived exertion post 1-mile walk were $12.1(\mathrm{SD}=1.7$; range=7-17), with the 
average consistent with moderate intensity activity defined as "somewhat hard." There were 32 women who were unable to complete the 1-mile walk in 20 minutes or less.

Table 2 summarizes characteristics of the women and their physical function across BMI categories. The ANOVA results show differences in all measures across the BMI categories except for timed chair stands. Pairwise comparisons for the 1-mile walk times indicate differences between all groups except between obese I and obese II, and between obese I and obese II categories. Women in the obese III category had an average 1-mile walk time of 20.8 minutes compared to 16.3 minute mean for those in the normal weight category.

When examining physical performance across categories of percent body fat (Table 3), ANOVA analysis found group differences in all measures except for age. Women who were classified as morbid obese (40-44.9\% fat) or super obese ( $>45 \%$ fat) had poorer performances for 1-mile walk time compared to other groups, including those in the obese category (30-39.9\% fat). Pairwise comparisons also revealed that women categorized as super obese ( $>45 \%$ fat) reported higher perceived exertion and longer times to complete chair stands than those in the lowest obese category (30-39.9\% fat).

Tables 4 and 5 shows the results for the hierarchical regression analysis investigating the association between the body composition measures with the 1-mile walk time and 10repetition timed chair stands, respectively. For 1-mile walk time, age, income, and comorbidity remained significant at step 2 for both BMI and percent body fat; whereas for10repetition chair stands, only age and smoking were significant at step 2 for both body composition measures. After adjusting for differences in age, education, income, smoking and comorbid conditions, the two body composition measures remained significant for predictors of both dependent measures.

For the 1-mile walk test, BMI increased the adjusted $R^{2}$ by 0.15 to 0.40 . The unstandardized coefficient of BMI was $0.19(p<0.001)$, indicating that for every one point of 
BMI increase, the time to walk a mile increased by 0.19 minutes ( $\sim 11.4$ seconds). BMI also increased the adjusted $\mathrm{R}^{2}$ of timed chair stands from 0.12 to a total $\mathrm{R}^{2}$ of 0.15 . The unstandardized coefficient of BMI on timed chair stands was $0.16(p=0.001)$, indicating that for every one point of BMI increase, the time to perform 10 chair stands increased by 0.16 seconds.

In the equation predicting time to walk a mile, percent fat increased the adjusted $\mathrm{R}^{2}$ from 0.15 to 0.31 . The unstandardized coefficient of percent fat was $0.13(p<0.001)$, indicating that for every one percent increase in body fat, the time to walk a mile increased by 0.13 minutes ( $\sim 8$ seconds). Percent fat also increased the adjusted $\mathrm{R}^{2}$ of timed chair stands by 0.12 to a total $\mathrm{R}^{2}$ of 0.19 . The unstandardized coefficient of percent fat on timed chair stands was $0.20(p<0.001)$, indicating that for every one percent increase in body fat, the time to perform 10 chair stands increased by 0.20 seconds.

\section{DISCUSSION}

This study examined the relationship between two measures of body composition (BMI and percent body fat) and physical performance measures among midlife and older rural women with prehypertension who were motivated to volunteer for lifestyle modification to reduce blood pressure. Overall this cohort of women had a high prevalence of obesity, regardless of how obesity was defined, and they were healthy, with $63 \%$ having no selfreported medical conditions. The results indicate that obesity, regardless of categorization method, related to the physical function in this cohort, particularly at the two higher categories of obesity. That women with these high levels of obesity would volunteer for lifestyle modification and complete these physical measures is encouraging.

The mean scores for the entire cohort for the walk-time and chair stands were similar to those reported by our team in a separate clinical trial for promoting healthy eating and activity that involved rural women ages 50-69, regardless of blood pressure status, who were 
from different regions of the state. ${ }^{37}$ In the current study, group differences were noted in measures of walk-time and perceived exertion post-walk across categories of BMI and percent body fat, whereas group differences were observed in timed chair stands across categories of percent body fat only.

Our findings are similar to the available normative data that indicate age-related declines are expected for the measures selected, and that other factors such as education, income, smoking and comorbidity may also influence physical performance. ${ }^{18,19,28}$ Age and smoking explained variance at step 2 in all the regression models. Income and comorbidity explained variance only in the 1-mile walk time. Education was not significant in any of the models, perhaps due in part to the large percentage of women $(n=237,82 \%)$ having some education beyond high school.

In all regression models, both measures of obesity explained additional variance in 1mile walk time and timed chair stands after adjustment for age, education, income, and comorbidity. These findings are meaningful. For example, the regression models for BMI predict a difference in performance in 1-mile walk time by nearly one minute ( 57 seconds) and a difference in 10-repetition chair stands by 1-second for a 5-unit change in BMI, the amount of BMI change equivalent to a BMI weight reclassification. To aid in interpretation, literature on the 1-mile walk test shows for healthy adults, ages 30-69, the mean walk-time increases by nearly 30 seconds for every decade in age. ${ }^{18}$ Research findings on the 10 repetition chair stands test indicates for healthy women, ages $20-85$, the mean time is approximately 1 -second greater for every five years in age. ${ }^{19}$ The regression models for percent body fat offer similar predictive changes as the BMI regression models for the 1-mile walk time and chair stand measures.

Group differences were noted for leg strength for categories of percent body fat but not $\mathrm{BMI}$, with average scores ranging from 12.2 seconds $(\mathrm{SD}=1.6)$ for women categorized as 
normal weight $(<25 \%$ fat) to 19.6 seconds $(\mathrm{SD}=4.6)$ for those categorized as super obese ( $>45 \%$ body fat), respectively. The scores we observed in women classified as super obese were similar to performances observed in individuals aged 70 in the original study by Csuka and McCarthy. ${ }^{19}$ As noted by Bouchard and Janssen, ${ }^{9}$ individuals with increased fat and decreased muscle strength have a greater decline in physical function than those with only an increase in percent body fat or a decrease in strength. Our research design did not address this issue. Our findings raise questions as to whether obese women who volunteered for this study had a higher level of muscle strength than other women in the community with similar age, obesity, and prehypertension, and/or whether obese women who have a certain threshold of aerobic capacity and/or muscle strength would be more likely to enroll in a lifestyle intervention.

Though declines in gait speed were noted in 1-mile walk times across both body composition categories, all groups had the ability to walk at a pace of $3 \mathrm{mph}$ or faster, with the exception of women in the BMI obese III group $\left(>40 \mathrm{~kg} / \mathrm{m}^{2}\right)$ who averaged $1.3 \mathrm{~m} / \mathrm{s}$ with walk-times of 20.8 minutes, which is close to a threshold consistent with functional limitation as reported by others for much shorter distances ( 8 -30 meters) ${ }^{8,10}$ The perceived exertion for completing the 1-mile walk was highest for those in the highest categories for both BMI and body fat, with average perceived exertion post-walk between "somewhat hard" and "hard (heavy)." When examining the net metabolic rates of women during walking, Browning and colleagues $^{38}$ found that the relative aerobic effort required to walk at a preferred speed is greater in obese versus normal weight women, which may explain our findings of increased perceived exertion with slower walk times. As noted in a 2011 ACSM Position Stand, ${ }^{26}$ relative intensity may be appropriate for goal setting in deconditioned individuals and exercise recommendations should be modified according to an individual's habitual activity, physical function, and health status. 
The bioelectrical impedance method used in this study was appropriate for a fieldbased study yet it has a large standard of error compared to dual-X-ray absorptiometry (DXA), though we did follow testing procedures for reducing errors due to hydration status. Shah and Braverman ${ }^{21}$ suggest that BMI may ignore the influence of muscle loss in aging women. Our findings would support this as women in the lowest obesity category by body fat (30-39.9\%) had an average BMI of $25.9(\mathrm{SD}=2.4)$ which is similar to the revised BMI score $\left(\geq 25 \mathrm{~kg} / \mathrm{m}^{2}\right.$ ) recommended for defining obesity in post-menopausal women, suggesting that the revised BMI score may be helpful to practitioners when defining obesity in a similar population. $^{21}$

The uniqueness of this study is that it examines the association of obesity and physical function across all categories of BMI and percent body fat using challenging performance measures that have not been reported in prior research, and it involves a large cohort of rural women from a vulnerable population. However, limitations are noted for this study. The cross-sectional design limits any interpretation for cause and effect. Our women were motivated to begin a lifestyle intervention to address their prehypertension and they met strict inclusion criteria, limiting the generalizability of our findings to the overall population of the region. There was potential for misclassification of women to weight categories, particularly the percent body fat categories, as we used a measure of bioelectric impedance suited for a field-trial as opposed to a more complex measure such as DXA. Though not collected in this cohort, accelerometer-reported physical activity may provide further insight into the association of obesity with physical function, and collection of such data would be recommended in future studies.

\section{CONCLUSIONS}

This study examined the obesity, by BMI and percent body fat, and physical function in a cohort of rural midlife and older rural women who were prehypertensive, able to walk 1-mile 
unassisted and motivated to enroll in lifestyle intervention. Women in the two highest categories of obesity, whether determined using BMI or percent body fat, met the inclusion criteria and enrolled in the program. Obesity, regardless of measurement method, was related to poorer performances in 1-mile walk times and 10-repetition chair stands in the highest weight categories, with implications for practitioners to assess and address physical performance in overweight and obese women when providing lifestyle modification interventions. 


\section{ACKNOWLEDGMENTS}

This study was funded by the National Institute of Nursing Research (NINR), National

Institutes of Health (NIH), Grant no. R01 NR04861 with support by a Research Support Fund from The Nebraska Medical Center and the University of Nebraska Medical Center and The Hygenic Corporation.

The authors thank Alicia Reinking and Julie Ehlers who served as project coordinators, and Cindy Ference and Judy Katzberg for their work completing assessments. Appreciation is extended to Denise Waibel-Rycek and Linda Erickson for their roles in participant recruitment and to Melody Hertzog, $\mathrm{PhD}$ for providing statistical expertise. 


\section{REFERENCES}

1. Flegal KM, Carroll MD, Kit BK, Ogden CL. Prevalence of obesity and trends in the distribution of body mass index among US adults, 1999-2010. JAMA. 2012;307(5):491-497.

2. Befort CA, Nazir N, Perri MG. Prevalence of obesity among adults from rural and urban areas of the united states: Findings from NHANES (2005-2008). J Rural Health. 2012;28(4):392-397.

3. Murray CJL, Kulkarni S, Ezzati M. Eight americas: New perspectives on U.S. health disparities. Am J Prev Med. 2005;29(5):4-10.

4. Hageman PA, Pullen CH, Hertzog M, Boeckner LS, Walker SN. Associations of cardiorespiratory fitness and fatness with metabolic syndrome in rural women with prehypertension. J Obes. 2012;2012:618728.

5. Agency for Healthcare Research and Quality (AHRQ). Special emphasis notice (SEN): AHRQ announces interest in priority populations research.

http:/grants.nih.gov/grants/guide/notice-files/NOT-HS-11-014.html. Updated April 13, 20112013.

6. National Institutes of Health, National Heart, Lung, and Blood Institute. Cardiovascular disease prevention in high-risk rural communities. workshop executive summary. Cardiovascular disease prevention in high-risk rural communities Web site. http://www.nhlbi.nih.gov/meetings/workshops/cvd_rural_workshop/report.htm. Updated June 15, 2010.

7. Houston DK, Ding J, Nicklas BJ, et al. The association between weight history and physical performance in the health, aging and body composition study. Int J Obes (Lond). 2007;31(11):1680-1687.

8. Stenholm S, Rantanen T, Alanen E, Reunanen A, Sainio P, Koskinen S. Obesity history as a predictor of walking limitation at old age. Obesity (Silver Spring). 2007;15(4):929-938. 
9. Bouchard DR, Janssen I. Dynapenic-obesity and physical function in older adults. $J$ Gerontol A Biol Sci Med Sci. 2010;65(1):71-77.

10. Vincent HK, Vincent KR, Lamb KM. Obesity and mobility disability in the older adult. Obes Rev. 2010;11(8):568-579.

11. Apovian CM, Frey CM, Wood GC, Rogers JZ, Still CD, Jensen GL. Body mass index and physical function in older women. Obes Res. 2002;10(8):740-747.

12. Bohannon RW, Brennan PJ, Pescatello LS, Marschke L, Hasson S, Murphy M. Adiposity of elderly women and its relationship with self-reported and observed physical performance. J Geriatr Phys Ther. 2005;28(1):10-13.

13. Hergenroeder AL, Brach JS, Otto AD, Sparto PJ, Jakicic JM. The influence of body mass index on self-report and performance-based measures of physical function in adult women. Cardiopulm Phys Ther J. 2011;22(3):11-20.

14. Hergenroeder AL, Wert DM, Hile ES, Studenski SA, Brach JS. Association of body mass index with self-report and performance-based measures of balance and mobility. Phys Ther. 2011;91(8):1223-1234.

15. LaRoche DP, Kralian RJ, Millett ED. Fat mass limits lower-extremity relative strength and maximal walking performance in older women. J Electromyogr Kinesiol. 2011;21(5):754-761.

16. Ling C, Kelechi T, Mueller M, Brotherton S, Smith S. Gait and function in class III obesity. J Obes. 2012;2012:257468.

17. Riebe D, Blissmer BJ, Greaney ML, Garber CE, Lees FD, Clark PG. The relationship between obesity, physical activity, and physical function in older adults. J Aging Health. 2009;21(8):1159-1178.

18. Kline GM, Porcari JP, Hintermeister R, et al. Estimation of $\mathrm{VO}_{2}$ max from a one-mile track walk, gender, age, and body weight. Med Sci Sports Exerc. 1987;19(3):253-259. 
19. Csuka M, McCarty DJ. Simple method for measurement of lower extremity muscle strength. Am J Med. 1985;78(1):77-81.

20. U.S. Department of Health and Human Services. The practical guide: Identification, evaluation, and treatment of overweight and obesity in adults. 2000;NIH Publication No. 004084.

21. Shah NR, Braverman ER. Measuring adiposity in patients: The utility of body mass index (BMI), percent body fat, and leptin. PLoS One. 2012;7(4):e33308.

22. Okorodudu DO, Jumean MF, Montori VM, et al. Diagnostic performance of body mass index to identify obesity as defined by body adiposity: A systematic review and metaanalysis. Int J Obes (Lond). 2010;34(5):791-799.

23. Blew RM, Sardinha LB, Milliken LA, et al. Assessing the validity of body mass index standards in early postmenopausal women. Obes Res. 2002;10(8):799-808.

24. Haskell WL, Lee IM, Pate RR, et al. Physical activity and public health: Updated recommendation for adults from the American College of Sports Medicine and the American Heart Association. Circulation. 2007;116(9):1081-1093.

25. Donnelly JE, Blair SN, Jakicic JM, Manore MM, Rankin JW, Smith BK. American College of Sports Medicine position stand. Appropriate physical activity intervention strategies for weight loss and prevention of weight regain for adults. Med Sci Sports Exerc. 2009;41(2):459-471.

26. Garber CE, Blissmer B, Deschenes MR, et al. American College of Sports Medicine position stand. Quantity and quality of exercise for developing and maintaining cardiorespiratory, musculoskeletal, and neuromotor fitness in apparently healthy adults: Guidance for prescribing exercise. Med Sci Sports Exerc. 2011;43(7):1334-1359. 27. Willis BL, Gao A, Leonard D, DeFina LF, Berry JD. Midlife fitness and the development of chronic conditions in later life. Archives of Internal Medicine. 2012;172(17):1333-1340. 
28. Koster A, Penninx BW, Newman AB, et al. Lifestyle factors and incident mobility limitation in obese and non-obese older adults. Obesity (Silver Spring). 2007;15(12):31223132.

29. Chobanian AV, Bakris GL, Black HR, et al. The seventh report of the joint national committee on prevention, detection, evaluation, and treatment of high blood pressure: The JNC 7 report. JAMA. 2003;289(19):2560-2572.

30. U.S. Department of Health and Human Services, National Institutes Health, National Heart, Lung,and Blood Institute. Your guide to lowering your blood pressure with DASH. http://www.nhlbi.nih.gov/health/public/heart/hbp/dash/new_dash.pdf. Published 1998. Updated April, 2006.

31. Perloff D, Grim C, Flack J, et al. Human blood pressure determination by sphygmomanometry. Circulation. 1993;88(5 Pt 1):2460-2470.

32. Cardinal BJ, Esters J, Cardinal MK. Evaluation of the revised physical activity readiness questionnaire in older adults. Med Sci Sports Exerc. 1996;28(4):468-472.

33. Xie X, Kolthoff N, Bärenholt O, Nielsen SP. Validation of a leg-to-leg bioimpedance analysis system in assessing body composition in postmenopausal women. Int J Obes Relat Metab Disord. 1999;23(10):1079-1084.

34. Utter A, Nieman D, Ward A, Butterworth D. Use of the leg-to-leg bioelectrical impedance method in assessing body-composition change in obese women. Am J Clin Nutr. 1999;69(4):603-607.

35. Hageman PA, Walker SN, Pullen CH, Pellerito P. Test-retest reliability of the rockport fitness walking test and other fitness measures in women ages 50-69 years. Issues on Aging. $2001 ; 24(2): 7-11$. 
36. Scherr J, Wolfarth B, Christle JW, Pressler A, Wagenpfeil S, Halle M. Associations between Borg's rating of perceived exertion and physiological measures of exercise intensity. European Journal of Applied Physiology. 2013;113(1):147-155.

37. Walker SN, Pullen CH, Boeckner L, et al. Clinical trial of tailored activity and eating newsletters with older rural women. Nurs Res. 2009;58(2):74-85.

38. Browning RC, Baker EA, Herron JA, Kram R. Effects of obesity and sex on the energetic cost and preferred speed of walking. J Appl Physiol. 2006;100(2):390-398. 
Table 1. Characteristics of Midlife and Older Rural Women $(n=289)$ who Volunteer for Lifestyle Modification for Reducing Blood Pressure.

\begin{tabular}{|c|c|c|}
\hline Characteristics & $\mathbf{n}$ & $\%$ \\
\hline \multicolumn{3}{|l|}{ Race and ethnicity } \\
\hline White (Non-Hispanic) & 283 & 97.3 \\
\hline Hispanic & 3 & 1.0 \\
\hline Other & 1 & 0.1 \\
\hline No response & 2 & 0.6 \\
\hline \multicolumn{3}{|l|}{ Rural Residency } \\
\hline On farm/ranch or in country & 82 & 28.4 \\
\hline In town $<2,500$ & 38 & 13.1 \\
\hline In town $2,500-19,999$ & 31 & 10.7 \\
\hline In town $20,000-49,999$ & 138 & 47.7 \\
\hline \multicolumn{3}{|l|}{ Education } \\
\hline High school or less & 52 & 18 \\
\hline Some college or more & 119 & 41 \\
\hline College graduate or above & 118 & 40.8 \\
\hline \multicolumn{3}{|l|}{ Household Income } \\
\hline$<\$ 20,000$ & 20 & 6.9 \\
\hline$\$ 20,000$ to $\$ 39,000$ & 62 & 21.5 \\
\hline$\$ 40,000$ to $\$ 59,999$ & 79 & 27.3 \\
\hline$\$ 60,000$ or higher & 127 & 43.9 \\
\hline No response & 1 & .1 \\
\hline \multicolumn{3}{|l|}{ Comorbid Conditions } \\
\hline Diabetes & 16 & 6 \\
\hline Coronary Artery Disease & 0 & 0 \\
\hline Heart attack & 3 & 1 \\
\hline Stroke & 3 & 1 \\
\hline Emphysema & 3 & 1 \\
\hline Asthma & 26 & 9 \\
\hline
\end{tabular}




\begin{tabular}{|l|c|c|}
\hline Arthritis & 67 & 23 \\
\hline Osteoporosis & 23 & 8 \\
\hline Broken hip & 1 & 0 \\
\hline Cancer & 8 & 3 \\
\hline
\end{tabular}


Table 2. Results for Age, Percent Fat and Measures of Physical Function across BMI

Categories $(n=289)$.

\begin{tabular}{|c|c|c|c|c|c|c|}
\hline \multirow[b]{2}{*}{ Variables } & \multicolumn{6}{|c|}{ BMI Classification } \\
\hline & $\begin{array}{c}\text { Normal } \\
\text { Weight } \\
\left(<25 \mathrm{~kg} / \mathrm{m}^{2}\right) \\
\text { Mean (SD) } \\
(\mathrm{n}=53)\end{array}$ & $\begin{array}{c}\text { Overweight } \\
(25-29.9 \\
\text { kg/m²) } \\
\text { Mean (SD) } \\
(n=109) \\
\end{array}$ & $\begin{array}{c}\text { Obese I } \\
(30-34.9 \\
\text { kg/m²) } \\
\text { Mean (SD) } \\
(n=82) \\
\end{array}$ & $\begin{array}{c}\text { Obese II } \\
(35-39.9 \\
\text { kg/m²) } \\
\text { Mean (SD) } \\
(n=35) \\
\end{array}$ & $\begin{array}{c}\text { Obese III } \\
(\geq 40 \\
\left.\mathrm{kg} / \mathrm{m}^{2}\right) \\
\text { Mean (SD) } \\
(\mathrm{n}=10) \\
\end{array}$ & $p$ \\
\hline Age (years) ${ }^{a}$ & $56.9(6.0)$ & $57.7(6.9)$ & $55.6(5.7)$ & $54.8(5.4)$ & $52.6(6.7)$ & 0.02 \\
\hline $\begin{array}{l}\text { Percent Body } \\
\text { Fat }^{\mathrm{b}}(\%)\end{array}$ & $32.2(4.9)$ & $39.3(3.4)$ & $44.5(2.5)$ & $47.6(2.9)$ & $49.9(3.0)$ & $<0.001$ \\
\hline $\begin{array}{l}\text { Waist } \\
\text { Circumference } \\
(\mathrm{cm})\end{array}$ & $81.8(7.2)$ & $93.7(6.9)$ & $103.9(6.9)$ & $111.6(7.6)$ & $123.5(9.2)$ & $<0.001$ \\
\hline $\begin{array}{l}\text { 1-Mile Walk } \\
\text { Time }^{\mathrm{d}} \text { (min) }\end{array}$ & $16.3(1.5)$ & $17.2(1.7)$ & $18.0(1.8)$ & $18.8(2.0)$ & $20.8(2.0)$ & $<0.001$ \\
\hline $\begin{array}{l}\text { 1-Mile Gait } \\
\text { Speed }^{\mathrm{e}}(\mathrm{m} / \mathrm{sec})\end{array}$ & $1.7(.1)$ & $1.6(.2)$ & $1.5(.1)$ & $1.4(.1)$ & $1.3(.1)$ & $<0.001$ \\
\hline $\begin{array}{l}\text { Borg Exertion } \\
\text { Score Post 1- } \\
\text { Mile Walk }\end{array}$ & $11.2(1.8)$ & $11.8(1.6)$ & $12.4(1.7)$ & $12.8(1.5)$ & $13.6(1.6)$ & $<0.001$ \\
\hline $\begin{array}{l}\text { 10-Repetition } \\
\text { Chair Stands } \\
\text { (sec) }\end{array}$ & $16.8(5.1)$ & $17.9(3.9)$ & $18.1(4.8)$ & $19.7(4.6)$ & $17.9(3.8)$ & 0.07 \\
\hline
\end{tabular}

${ }^{\mathrm{a}}$ Bonferroni-adjusted post hoc pairwise comparisons were all non-significant $(\mathrm{p}>0.05)$.

${ }^{\mathrm{b}}$ All groups are significantly different $(p<0.001)$ except for obese II compared to obese III.

${ }^{\mathrm{c}}$ All groups are significantly different $(p<0.001)$.

${ }^{\mathrm{d}}$ All groups are significantly different from each other $(p<0.05)$ except for obese I compared to obese II

${ }^{\mathrm{e}}$ All groups are significantly different from each other $(p<0.05)$ except for obese II compared to obese I and obese III.

${ }^{\mathrm{f}}$ Normal weight is significantly different than obese I, II, and III $(p<0.001)$; The overweight group is significantly different than obese II and III $(p<<0.05)$.

${ }^{\mathrm{g}}$ For obese I, $\mathrm{n}=81$. 
Table 3. Results for Age, BMI and Measures of Physical Function across Percent Body Fat Categories $(n=289)$.

\begin{tabular}{|c|c|c|c|c|c|c|}
\hline \multirow[b]{2}{*}{ Variables } & \multicolumn{6}{|c|}{ Percent Body Fat Classification } \\
\hline & $\begin{array}{c}\text { Normal Weight } \\
(<25 \%) \\
\text { Mean (SD) } \\
(\mathbf{n}=5) \\
\end{array}$ & $\begin{array}{c}\text { Overweight } \\
(25-29.9 \%) \\
\text { Mean (SD) } \\
(n=11) \\
\end{array}$ & $\begin{array}{c}\text { Obese } \\
(30-39.9 \%) \\
\text { Mean (SD) } \\
(n=106) \\
\end{array}$ & $\begin{array}{c}\text { Morbid Obese } \\
(40-44.9 \%) \\
\text { Mean (SD) } \\
(n=88) \\
\end{array}$ & $\begin{array}{c}\text { Super Obese } \\
(>45 \%) \\
\text { Mean (SD) } \\
(n=79) \\
\end{array}$ & $p$ \\
\hline Age (years) & $50.0(4.6)$ & $57.1(5.5)$ & $56.5(6.4)$ & $57.3(6.4)$ & $55.7(6.1)$ & 0.08 \\
\hline BMI $\left(\mathrm{kg} / \mathrm{m}^{2}\right)^{\mathrm{a}}$ & $19.8(1.5)$ & $22.1(1.7)$ & $25.9(2.4)$ & 30.7 (2.9) & $35.6(4.1)$ & $<0.001$ \\
\hline $\begin{array}{l}\text { Waist } \\
\text { Circumference } \\
\text { (cm) }\end{array}$ & $69.6(1.7)$ & $77.8(3.4)$ & $88.7(6.5)$ & $100.7(7.2)$ & $110.7(8.6)$ & $<0.001$ \\
\hline $\begin{array}{l}\text { 1-Mile Walk } \\
\text { Time }^{\mathrm{c}} \text { (min) }\end{array}$ & $15.6(1.0)$ & $16.9(1.9)$ & $16.6(1.6)$ & $18.0(2.0)$ & $18.6(1.9)$ & $<0.001$ \\
\hline $\begin{array}{l}\text { 1-Mile Gait } \\
\text { Speed }^{\mathrm{d}}(\mathrm{m} / \mathrm{sec})\end{array}$ & $1.7(0.1)$ & $1.6(0.2)$ & $1.6(0.1)$ & $1.5(0.2)$ & $1.5(0.1)$ & $<0.001$ \\
\hline $\begin{array}{l}\text { Borg Exertion } \\
\text { Score Post 1- } \\
\text { Mile Walk }\end{array}$ & $11.2(3.0)$ & $11.7(0.9)$ & $11.7(1.8)$ & $12.0(1.8)$ & $12.8(1.5)$ & $<0.001$ \\
\hline $\begin{array}{l}\text { 10-Repetition } \\
\text { Chair Stands }{ }^{\mathrm{f}} \\
(\mathrm{sec})\end{array}$ & $12.2(1.6)$ & $16.3(3.9)$ & $17.2(4.3)$ & $18.0(4.4)$ & $19.6(4.6)$ & $<0.001$ \\
\hline
\end{tabular}

${ }^{a}$ All groups are significantly different $(p<0.001)$.

${ }^{\mathrm{b}}$ All groups are significantly different $(p<0.001)$ except for normal weight compared to the overweight group.

${ }^{\mathrm{c}}$ The normal weight group is significantly different than the morbid obese and the super obese groups $(p<0.05)$;

The overweight group is significantly different than the super obese group $(p=0.04)$. The obese group is significantly different than the morbid obese and super obese groups $(p<0.001)$.

${ }^{\mathrm{d}}$ The normal weight group is significantly different than the morbid obese and super obese groups $(p<0.05)$.

The overweight group is significantly different than the super obese group $(p=0.02)$;

The obese group is significantly different than the morbid obese and super obese groups $(p<0.001)$.

${ }^{\mathrm{e}}$ The obese group is significantly different than the super obese group $(p<0.001)$.

${ }^{\mathrm{f}}$ The normal weight group is significantly different than the morbid obese and super obese groups $(p<0.04)$.

The obese group is significantly different than the super obese group ( $p=0.003) .{ }^{g}$ For obese group $(n=105)$. 
Table 4. Regressions of 1-Mile Walk Time on Body Composition (BMI or Percent Body Fat) Controlling for Background Variables ( $\mathrm{n}=289)$.

\begin{tabular}{|l|c|c|c|c|c|c|c|c|c|}
\hline \multicolumn{1}{|c|}{ Variables } & \multicolumn{3}{|c|}{ Step 1 } & \multicolumn{3}{c|}{$\begin{array}{c}\text { Step 2 } \\
\text { BMI }\end{array}$} & \multicolumn{3}{c|}{$\begin{array}{c}\text { Step 2 } \\
\text { Percent Body Fat }\end{array}$} \\
\hline & $\mathrm{b}$ & $\mathrm{SE}^{\mathrm{a}}$ & $\boldsymbol{p}$ & $\mathrm{b}$ & $\mathrm{SE}^{\mathrm{a}}$ & $\boldsymbol{p}$ & $\mathrm{b}$ & $\mathrm{SE}^{\mathrm{a}}$ & $\boldsymbol{p}$ \\
\hline $\begin{array}{l}\text { Control } \\
\text { Variables }\end{array}$ & & & & & & & & & \\
\hline Age & 0.05 & 0.02 & 0.005 & 0.08 & 0.02 & $<0.001$ & 0.05 & 0.02 & 0.002 \\
\hline Education & -0.05 & 0.08 & 0.52 & -0.04 & 0.07 & 0.59 & -0.04 & 0.07 & 0.57 \\
\hline Income & -0.37 & 0.12 & 0.002 & -0.22 & 0.10 & 0.03 & -0.25 & 0.11 & 0.02 \\
\hline Smoking & 0.84 & 0.48 & 0.08 & 1.20 & 0.41 & 0.003 & 0.90 & 0.43 & 0.04 \\
\hline Comorbidity & 0.56 & 0.14 & $<0.001$ & 0.47 & 0.12 & $<0.001$ & 0.56 & 0.13 & $<0.001$ \\
\hline $\begin{array}{l}\text { Body } \\
\text { Composition }\end{array}$ & & & & & & & & & \\
\hline BMI & & & & 0.19 & 0.02 & $<0.001$ & & & \\
\hline \% Body Fat & & & & & & & 0.13 & 0.02 & $<0.001$ \\
\hline & & & & & & & & & \\
\hline Adjusted $R^{2}$ & 0.15 & & & 0.40 & & & 0.31 & & \\
\hline
\end{tabular}

${ }^{a}$ At step 1, both analyses include the same control variables and therefore results are identical.

Abbreviation: SE, standard Error 
Table 5. Regressions of 10-Repetition Chair Stands on Body Composition (BMI or Percent Body Fat) Controlling for Background Variables $(\mathrm{n}=288)$.

\begin{tabular}{|l|c|c|c|c|c|c|c|c|c|}
\hline Variables & \multicolumn{3}{|c|}{ Step 1 $^{\mathrm{a}}$} & \multicolumn{3}{c|}{$\begin{array}{c}\text { Step 2 } \\
\text { BMI }\end{array}$} & \multicolumn{3}{c|}{$\begin{array}{c}\text { Step 2 } \\
\text { Percent Body Fat }\end{array}$} \\
\hline & $\mathrm{b}$ & $\mathrm{SE}^{\mathrm{b}}$ & $\boldsymbol{p}$ & $\mathrm{b}$ & $\mathrm{SE}^{\mathrm{b}}$ & $\boldsymbol{p}$ & $\mathrm{b}$ & $\mathrm{SE}^{\mathrm{b}}$ & $\boldsymbol{p}$ \\
\hline Control Variables & & & & & & & & & \\
\hline Age & 0.21 & 0.04 & $<0.001$ & 0.24 & 0.04 & $<0.001$ & 0.21 & 0.04 & $<0.001$ \\
\hline Education & 0.02 & 0.19 & 0.93 & 0.03 & 0.19 & 0.89 & 0.03 & 0.18 & 0.87 \\
\hline Income & -0.44 & 0.27 & 0.11 & -0.31 & 0.27 & 0.24 & -0.25 & 0.26 & 0.34 \\
\hline Smoking & 2.67 & 1.11 & 0.02 & 2.97 & 1.10 & 0.007 & 2.77 & 1.07 & 0.01 \\
\hline Comorbidity & 0.35 & 0.33 & 0.30 & 0.27 & 0.33 & 0.41 & 0.34 & 0.32 & 0.28 \\
\hline Body Composition & & & & & & & & & \\
\hline BMI & & & & 0.16 & 0.05 & 0.001 & & & \\
\hline \% Body Fat & & & & & & & 0.20 & 0.04 & $<0.001$ \\
\hline & & & & & & & & & \\
\hline Adjusted $R^{2}$ & 0.12 & & & 0.15 & & & 0.19 & & \\
\hline
\end{tabular}

${ }^{a}$ At step 1, both analyses include the same control variables and therefore results are identical. ${ }^{\mathrm{b}} \mathrm{SE}=$ Standard Error 